\title{
Optimalisasi Basis Untuk Formulasi Sediaan Lip Cream
}

\author{
Jessica*, Laode Rijai, Hanggara Arifian
}

\author{
Laboratorium Penelitian dan Pengembangan Kefarmasian "Farmaka Tropis", \\ Fakultas Farmasi, Universitas Mulawarman, Samarinda, Indonesia \\ *Email: cikejess22@gmail.com
}

\begin{abstract}
Abstrak
Lip cream merupakan salah satu kosmetik jenis pewarna bibir yang saat ini banyak diminati konsumen. Kualitas lip cream salah satunya dipengaruhi oleh komponenkomponen penyusun basisnya, terutama wax sebagai thickener. Tujuan penelitian ini adalah untuk memperoleh formula optimal dari basis lip cream yang memenuhi persyaratan farmasetika. Penentuan formula basis optimal lip cream dilakukan melalui variasi jumlah thickener. Penelitian ini menggunakan carnauba wax dan microcrystaline wax sebagai thickener agent. Evaluasi karakteristik basis lip cream yang dilakukan meliputi uji organoleptis, uji homogenitas, dan uji fisika kimia (daya sebar, daya lekat, viskositas dan $\mathrm{pH}$ ), serta uji stabilitas basis lip cream menggunakan metode Freeze-Thaw selama 16 hari. Hasil penelitian diperoleh F7 (kombinasi carnauba wax dan microcrystaline wax dengan perbandingan 6\%:9\%) sebagai formula basis lip cream paling optimal. Formula F7 menghasilkan karakteristik organoleptis berwarna putih gading, berbau khas vanilin, berbentuk semipadat, dan homogen. Kemudian hasil uji karakteristik fisika dan kimia menunjukkan daya sebar $6,1 \mathrm{~cm}$, daya lekat lebih dari 60 detik, nilai viskositas $18.000 \mathrm{cPs}$ dan nilai $\mathrm{pH} 4,38$. Formula F7 juga stabil terhadap pengaruh perubahan suhu selama 16 hari.
\end{abstract}

Kata Kunci: lip cream, optimasi formula, carnauba wax, microcrystaline wax

\begin{abstract}
Lip cream is one of the cosmetics that is currently in great demand by consumers. The quality of lip cream is influenced by the basic constituent components, especially wax as thickener. The purpose of this study was to obtain the optimal lip cream formula that met pharmaceutical requirements. The optimal lip cream formula is determined by modifying the amount of thickener. This study used carnauba wax and microcrystaline wax as thickener agents. Evaluation of lip cream formula characteristics included organoleptic test, homogeneity test, physicochemical test (dispersion test, adhesion test, viscosity and pH test), and stability test of lip cream formula using the Freeze-Thaw method for 16 days. Formula F7 produces organoleptic characteristics, that is, produces ivory white colour, has a distinctive aroma of vanillin, forms semi-solid constituent, and produces a homogeneous mixture. Then, the results of the physicochemical characteristic test, among others, have a spread range of $6.1 \mathrm{~cm}$, a sticking time of more than 60 seconds, a viscosity
\end{abstract}


value of 18,000 cPs and a $\mathrm{pH}$ value of 4.38. Formula $F 7$ is also stable against the effects of temperature changes for 16 days.

Keywords: lip cream, formula optimation, carnauba wax, microcrystaline wax

DOI: https://doi.org/10.25026/mpc.v8i1.332

\section{PENDAHULUAN}

Kosmetik adalah sediaan atau paduan bahan yang siap untuk digunakan pada bagian luar badan (epidermis, rambut, kuku, bibir dan organ kelamin bagian luar), gigi dan rongga mulut untuk membersihkan, menambah daya tarik, mengubah penampilan, melindungi supaya tetap dalam keadaan baik, memperbaiki bau badan tetapi tidak dimaksudkan untuk mengobati atau menyembuhkan suatu penyakit [1]. Salah satu kosmetika dekoratif yang paling populer saat ini adalah pewarna bibir. Adapun sediaan pewarna bibir terdapat dalam berbagai bentuk, seperti cairan, krayon, dan krim. Saat ini pewarna bibir yang disukai adalah jenis sediaan pewarna bibir yang jika dilekatkan pada bibir akan memberikan selaput warna yang kering [2]. Sediaan pewarna bibir berbentuk krim atau disebut lip cream lebih diminati oleh konsumen karena dapat melembabkan bibir dalam waktu yang lama dibandingkan dalam bentuk padat, juga membuat bibir menjadi lebih mengkilap serta menghasilkan warna yang lebih homogen atau merata pada bibir [3].

Lip cream merupakan sediaan pewarma bibir berbentuk semipadat. Komposisi lip cream sama halnya dengan sediaan kosmetika dekoratif pada umumnya yaitu terdiri atas bahan aktif berupa zat warna dalam berbagai bahan dasar atau basis. Menurut Tranggono, syarat lip cream yang baik yaitu dapat melapisi bibir dan melekat dengan baik tetapi tidak lengket terhadap kulit bibir, tahan di bibir dalam jangka waktu yang lama, tidak menimbulkan iritasi atau alergi pada kulit bibir, dapat melembabkan kulit bibir, memberikan warna yang merata dan menarik pada bibir [4].

Salah satu parameter kualitas lip
cream ditentukan oleh komponen penyusun basis lip cream. Bentuk fisik dari sediaan juga memegang peranan penting untuk menarik minat konsumen. Komponen yang sangat mempengaruhi bentuk dan stabilitas fisik lip cream adalah basis wax. Pemilihan dan perbandingan jumlah basis wax yang digunakan akan mempengaruhi karakteristik lip cream. Beberapa jenis basis wax yang sering digunakan dalam pembuatan sediaan lip cream adalah carnauba wax, paraffin wax, beeswax, candelilla wax, dan spermaceti [5].

Oleh karena itu tujuan penelitian ini adalah untuk memperoleh formula optimal dari basis lip cream yang memenuhi persyaratan lip cream secara farmasetika serta stabil secara fisikokimia. Pembuatan dan penentuan formula basis yang optimal dilakukan melalui modifikasi perbandingan bahan wax, evaluasi karakteristik sediaan dan uji stabilitas formula basis. Teknik evaluasi yang dilakukan antara lain, pengujian organoleptis, homogenitas, uji $\mathrm{pH}$, pengukuran viskositas, uji daya sebar dan uji daya lekat. 


\section{METODE PENELITIAN}

\section{Bahan}

Bahan yang digunakan dalam penelitian ini antara lain: microcrystaline wax, carnauba wax, setil alkohol, kaolin, castor oil, dimethicone, titanium dioksida, tokoferol, vanilin dan aquades.

\section{Peralatan}

Peralatan yang digunakan dalam penelitian ini antara lain: timbangan analitik, cawan porselin, hot plate, batang pengaduk, gelas kimia, sendok tanduk, spatel logam, mortar dan stamper, $\mathrm{pH}$ meter, kaca objek, plat kaca datar, anak timbang, lemari pendingin, oven dan viskometer Rion VT-04F.

\section{PROSEDUR}

\section{Formulasi Basis Lip cream}

Pembuatan basis diawali dengan peleburan lemak dan lilin pada suhu $85^{\circ} \mathrm{C}$. Bahan-bahan pada fase tersebut yaitu castor oil, carnauba wax, microcrystaline wax, setil alkohol, dimethicon. Setelah bahan-bahan tersebut melebur, dibiarkan hingga suhu turun menjadi $65^{\circ} \mathrm{C}$ kemudian dipindahkan ke dalam mortir yang telah dipanaskan sambil digerus perlahan. Dimasukkan tokoferol, titanium dioksida, kaolin dan vanilin sedikit demi sedikit sambil digerus terus hingga homogen. Perbandingan jumlah thickener pada basis dapat dilihat pada Tabel 1 .

\section{Evaluasi Basis Lip Cream}

Evaluasi terhadap formula basis lip cream yang telah dibuat meliputi evaluasi karakteristik dan stabilitas fisik.

\section{Evaluasi Karakteristik Basis Lip cream Organoleptis}

Penetapan organoleptis dilakukan menggunakan panca indera dalam mendeskripsikan bentuk, warna, bau dan rasa. Diamati masing-masing sediaan lip cream terhadap bentuk, warna dan baunya kemudian dicatat hasilnya [6]. Basis lip cream biasanya berupa sediaan setengah padat berwarna putih. Bahan vanilin diharapkan memberi aroma khas pada basis lip cream yang diformulasi.

\section{Uji Homogenitas}

Masing-masing sediaan lip cream dioleskan dalam jumlah tertentu pada kaca objek. Sediaan harus menunjukkan susunan yang homogen dan tidak terlihat adanya butir-butir kasar [7].

\section{Uji Viskositas}

Masing-masing sediaan lip cream diamati tingkat kekentalannya dengan cara diukur menggunakan viskometer Rion. Sediaan dimasukkan secukupnya ke dalam cup, kemudian dipasang spindle nomor 2 dan rotor dijalankan. Diamati nilai viskositas yang ditunjukkan oleh alat, nilai viskositas yang baik untuk sediaan lip cream yaitu 10.000-20.000 cPs [8].

\section{Uji Daya Sebar}

Pengujian dilakukan dengan cara menimbang $1 \mathrm{~g}$ masing-masing sediaan lip cream dan diletakkan di tengahtengah dua buah kaca datar. Kemudian ditambahkan $125 \mathrm{~g}$ beban dan didiamkan selama 1 menit lalu dicatat diameter lip cream yang menyebar. Daya sebar yang baik untuk sediaan setengah padat yaitu $5-7 \mathrm{~cm} \mathrm{[9].}$

\section{Uji Daya Lekat}

Pengujian dilakukan dengan cara meletakkan lip cream di atas kaca objek. Diletakkan kaca objek lain di atas lip cream tersebut. Kemudian ditekan dengan beban $1 \mathrm{~kg}$ selama 5 menit. Kaca objek dipasang pada alat tes dengan ketinggian $50 \mathrm{~cm}$ dari permukaan tanah dan dilepaskan beban seberat 80 gram yang dipasang pada kaca objek. Dicatat waktu (s) yang diperlukan hingga kaca objek terlepas. Diperlukan waktu $>60$ detik agar sediaan dikatakan memiliki daya lekat yang baik [9]. 


\section{Nilai pH}

Pengukuran $\mathrm{pH}$ dilakukan menggunakan alat $\mathrm{pH}$ meter yang telah dikalibrasi. Kemudian elektroda yang telah dikalibrasi dicelupkan ke dalam basis yang telah dibuat. Diamati nilai $\mathrm{pH}$ yang ditunjukkan oleh alat $\mathrm{pH}$ meter hingga konstan. Angka yang ditunjukkan $\mathrm{pH}$ meter dicatat sebagai nilai $\mathrm{pH}$ sediaan. $\mathrm{pH}$ sediaan lip cream harus sesuai dengan $\mathrm{pH}$ bibir yaitu 3,8-4,7 [10].

\section{Uji Stabilitas Basis Lip cream}

Pengujian stabilitas fisik dilakukan dengan menggunakan metode Freeze Thaw dan kondisi penyimpanan pada suhu ruang $\left(25^{\circ} \mathrm{C}\right)$. Caranya yaitu masing-masing formula sediaan disimpan secara bergantian pada suhu $4^{\circ} \mathrm{C}$ selama 48 jam, kemudian dipindahkan ke suhu $40^{\circ} \mathrm{C}$ selama 48 jam (terhitung 1 siklus). Kemudian dilanjutkan dengan cara yang sama selama 4-6 siklus [11]. Sepanjang pergantian siklus, basis lip cream dievaluasi organoleptis, homogenitas, $\mathrm{pH}$ serta ada tidaknya pemisahan fase yang terjadi.

Tabel 1. Formula Optimasi Basis Lip cream dengan berbagai variasi konsentrasi wax

\begin{tabular}{cccccccc}
\hline \multirow{2}{*}{ Bahan } & \multicolumn{7}{c}{ Formula $(\%)$} \\
\cline { 2 - 8 } & $\mathrm{F} 1$ & $\mathrm{~F} 2$ & $\mathrm{~F} 3$ & $\mathrm{~F} 4$ & $\mathrm{~F} 5$ & $\mathrm{~F} 6$ & $\mathrm{~F} 7$ \\
\hline Carnauba wax & 15 & - & 7,5 & 10 & 5 & 9 & 6 \\
\hline Microcrystaline wax & - & 15 & 7,5 & 5 & 10 & 6 & 9 \\
\hline Castor Oil & 60 & 60 & 60 & 60 & 60 & 60 & 60 \\
\hline Setil Alkohol & 2 & 2 & 2 & 2 & 2 & 2 & 2 \\
\hline Kaolin & 3 & 3 & 3 & 3 & 3 & 3 & 3 \\
\hline Dimethicone & 10 & 10 & 10 & 10 & 10 & 10 & 10 \\
\hline Tokoferol & 0,05 & 0,05 & 0,05 & 0,05 & 0,05 & 0,05 & 0,05 \\
\hline Titanium Dioksida & 0,5 & 0,5 & 0,5 & 0,5 & 0,5 & 0,5 & 0,5 \\
\hline Vanilin & $\mathrm{qs}$ & $\mathrm{qs}$ & $\mathrm{qs}$ & $\mathrm{qs}$ & $\mathrm{qs}$ & $\mathrm{qs}$ & $\mathrm{qs}$ \\
\hline
\end{tabular}

\section{HASIL DAN PEMBAHASAN}

\section{Evaluasi Karakteristik Organoleptis dan Homogenitas}

Hasil optimasi basis lip cream yang diperoleh melalui formulasi dan evaluasi karakteristik organoleptis dan homogenitas F1 hingga F7 (Tabel 2) yaitu seluruhnya memiliki organoleptis berwarna putih gading, aroma khas vanilin dan berbentuk semipadat. Warna putih gading pada basis dipengaruhi oleh wax yang digunakan. carnauba wax berwarna kuning dan microcrystalline wax berwarna putih kekuningan, sehingga campuran kedua wax membentuk warna putih gading pada basis. Aroma khas vanilin diperoleh dari bahan vanilin yang digunakan. Dan bentuk semipadat terbentuk karena basis mengandung fase lemak dan fase minyak yang lebur bersama ketika dipanaskan.

Homogenitas ditentukan dengan mengamati ada tidaknya butiran kasar pada basis. Adanya butiran kasar menunjukkan bahwa bahan-bahan penyusun basis belum homogen saat formulasi. Hasil evaluasi diperoleh F1, F3 dan F6 kurang homogen, sementara F2, F4, F5 dan F7 homogen.

\section{Evaluasi Karakteristik Fisika dan Kimia}

Hasil evaluasi karakteristik fisika dan kimia dari tiap formula (Tabel 3) cukup beragam dibandingkan dengan hasil evaluasi karakteristik organleptis dan 
homogenitas. Parameter yang diuji meliputi viskositas, daya sebar, daya lekat, dan $\mathrm{pH}$.

Nilai viskositas yang baik untuk sediaan lip cream yaitu 10.000-20.000 cPs maka basis lip cream harus memenuhi nilai viskositas tersebut. Hasil pengujian menunjukkan beberapa formula memiliki nilai viskositas yang tidak termasuk dalam rentang nilai viskositas yang diharapkan yaitu F2 dan F6. F2 (microcrystaline wax $15 \%$ ) memiliki nilai viskositas jauh dibawah rentang yaitu sekitar $<5.000 \mathrm{cPs}$ dan sebaliknya F6 (carnauba wax 9\%: microcrystalline wax 6\%) memiliki nilai viskositas diatas rentang yaitu $25.000 \mathrm{cPs}$. Berdasarkan hasil tersebut diketahui bahwa jenis dan konsentrasi wax yang digunakan mempengaruhi viskositas basis. Jika dibandingkan, basis yang mengandung carnauba wax akan memiliki viskositas yang cukup tinggi dibandingkan dengan basis yang mengandung microcyrstaline wax.

Pengujian daya sebar bertujuan untuk mengetahui kemampuan atau daya sebar basis. Hal ini merupakan simulasi daya sebar sediaan ketika diaplikasikan ke permukaan bibir. Hasil pengujian menunjukkan hanya F6 dengan daya sebar $4 \mathrm{~cm}$ yang tidak memenuhi persyaratan daya sebar yang baik $(5-7 \mathrm{~cm})$. Hal ini dapat dipengaruhi oleh viskositas basis, dimana F6 memiliki viskositas yang cukup tinggi.

Uji daya lekat bertujuan untuk mengetahui kemampuan atau daya melekat basis. Sama halnya dengan uji daya sebar, hal ini juga merupakan simulasi daya lekat sediaan ketika diaplikasikan ke permukaan bibir. Hasil pengujian diperoleh bahwa seluruh formula menunjukkan daya lekat lebih dari 60 detik. Artinya ketika sediaan dengan basis formula tersebut diaplikasikan pada bibir maka sediaan dapat melekat dengan baik. Pengujian ini cukup penting dilakukan terutama untuk sediaan lip cream yang harus memenuhi pesyaratan lip cream yang baik yaitu salah satunya dapat melekat dengan baik namun tidak lengket terhadap permukaan bibir.
Pengujian $\mathrm{pH}$ bertujuan untuk mengetahui tingkat keasaman basis. $\mathrm{pH}$ yang tidak sesuai dapat menyebabkan iritasi pada bibir. $\mathrm{pH}$ sediaan harus sesuai dengan pH bibir yaitu 3,8- 4,7. Berdasarkan hasil pengujian diperoleh satu-satunya formula yang memenuhi nilai $\mathrm{pH}$ yang baik yaitu $\mathrm{F} 7$ dengan nilai $\mathrm{pH}$ 4,38 .

Dari seluruh hasil evaluasi karakteristik basis, diperoleh formula basis F7 yang memenuhi seluruh persyaratan farmasetika basis lip cream yang baik sehingga F7 diuji stabilitasnya untuk mengetahui apakah formula basis stabil selama masa penyimpanan sehingga layak digunakan sebagai formula basis dalam pembuatan lip cream.

\section{Uji Stabilitas Basis Optimal Karakteristik}

Uji stabilitas terhadap basis dilakukan untuk melihat kestabilan basis selama masa penyimpanan. Uji stabilitas dilakukan dengan menggunakan dua pengaruh suhu yaitu suhu ruang $\left(25^{\circ} \mathrm{C}\right)$ dan Freeze-Thaw $\left(4^{\circ} \mathrm{C}\right.$ dan $\left.40^{\circ} \mathrm{C}\right)$. Metode Freeze-Thaw merupakan salah satu metode uji stabilitas dipercepat. Menurut Asyifaa dkk, uji stabilitas dipercepat digunakan untuk membantu mengetahui masa simpan suatu sediaan yang dipengaruhi oleh perubahan suhu yang berbeda [12]. Melalui perubahan suhu juga dapat diamati ada tidaknya keterpisahan fase dalam basis sediaan semipadat karena perbedaan fase pada komponen-komponen yang digunakan dalam formulasi basis.

Data hasil uji stabilitas terhadap formula basis lip cream F7, menunjukkan bahwa basis stabil baik dalam penyimpanan dengan pengaruh perubahan suhu yang signifikan (Tabel 4) maupun penyimpanan pada suhu ruang (Tabel 5). pH basis masih berubah-ubah namun cenderung stabil dan dalam rentang $\mathrm{pH}$ yang sesuai dengan $\mathrm{pH}$ bibir. 


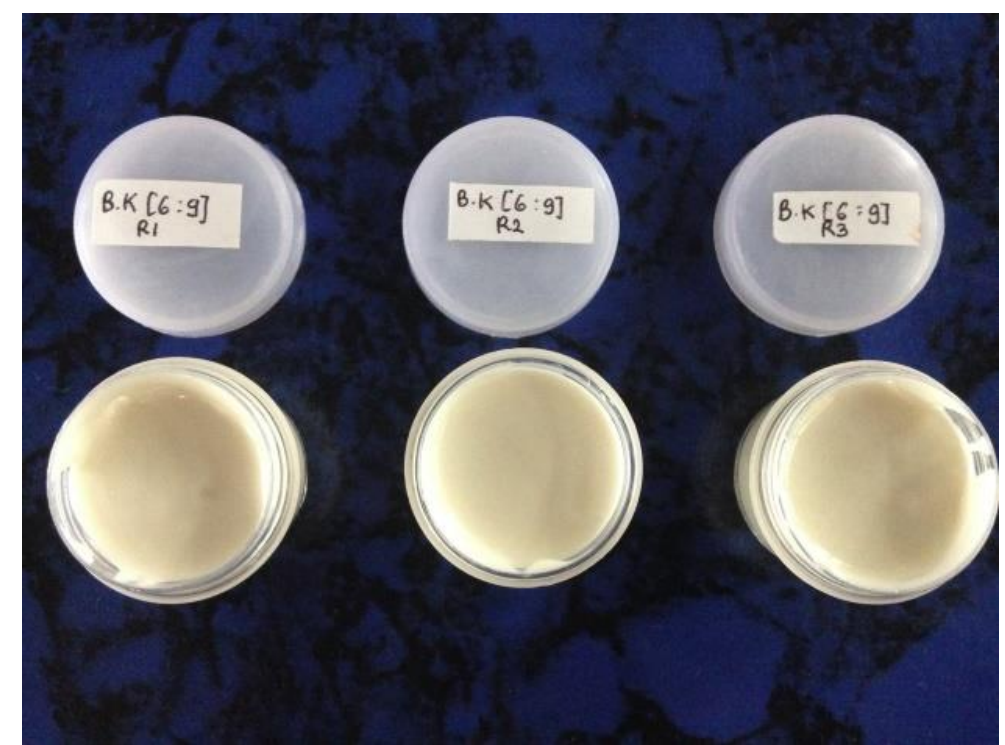

Gambar 1. Basis F7

Tabel 2. Evaluasi Karakteristik Organoleptis dan Homogenitas

\begin{tabular}{|c|c|c|c|c|c|c|c|}
\hline \multirow{2}{*}{ Parameter Uji } & \multicolumn{7}{|c|}{ Formula } \\
\hline & F1 & F2 & F3 & F4 & F5 & F6 & F7 \\
\hline \multicolumn{8}{|l|}{ Organoleptis } \\
\hline 1. Konsistensi & $\begin{array}{l}\text { Semi- } \\
\text { padat }\end{array}$ & $\begin{array}{l}\text { Semi- } \\
\text { padat }\end{array}$ & $\begin{array}{l}\text { Semi- } \\
\text { padat }\end{array}$ & $\begin{array}{l}\text { Semi- } \\
\text { padat }\end{array}$ & $\begin{array}{l}\text { Semi- } \\
\text { padat }\end{array}$ & Semi-padat & $\begin{array}{l}\text { Semi- } \\
\text { padat }\end{array}$ \\
\hline 2. Warna & $\begin{array}{l}\text { Putih } \\
\text { gading }\end{array}$ & $\begin{array}{l}\text { Putih } \\
\text { gading }\end{array}$ & $\begin{array}{l}\text { Putih } \\
\text { gading }\end{array}$ & $\begin{array}{l}\text { Putih } \\
\text { gading }\end{array}$ & $\begin{array}{l}\text { Putih } \\
\text { gading }\end{array}$ & $\begin{array}{l}\text { Putih } \\
\text { gading }\end{array}$ & $\begin{array}{l}\text { Putih } \\
\text { gading }\end{array}$ \\
\hline 3. Bau & $\begin{array}{c}\text { Khas } \\
\text { vanilin }\end{array}$ & $\begin{array}{c}\text { Khas } \\
\text { vanilin }\end{array}$ & $\begin{array}{c}\text { Khas } \\
\text { vanilin }\end{array}$ & $\begin{array}{l}\text { Khas } \\
\text { vanilin }\end{array}$ & $\begin{array}{c}\text { Khas } \\
\text { vanilin }\end{array}$ & $\begin{array}{c}\text { Khas } \\
\text { vanilin }\end{array}$ & $\begin{array}{c}\text { Khas } \\
\text { vanilin }\end{array}$ \\
\hline Homogenitas & $\begin{array}{c}\text { Kurang } \\
\text { homogen }\end{array}$ & Homogen & $\begin{array}{c}\text { Kurang } \\
\text { homogen }\end{array}$ & Homogen & Homogen & $\begin{array}{c}\text { Kurang } \\
\text { homogen }\end{array}$ & Homogen \\
\hline
\end{tabular}

Tabel 3. Evaluasi Karakteristik Fisika dan Kimia

\begin{tabular}{cccccccc}
\hline \multirow{2}{*}{ Parameter Uji } & \multicolumn{7}{c}{ Formula } \\
\cline { 2 - 8 } & F1 & F2 & F3 & F4 & F5 & F6 & F7 \\
\hline Viskositas (cPs) & 12.500 & $<5.000$ & 15.000 & 20.000 & 12.000 & 25.000 & 18.000 \\
\hline Daya Sebar (cm) & 5,7 & 6,6 & 5,15 & 5,5 & 5,4 & 4 & 6,1 \\
\hline Daya Lekat (detik) & $>60$ & $>60$ & $>60$ & $>60$ & $>60$ & $>60$ & $>60$ \\
\hline pH & 4,94 & 5,12 & 5,15 & 6,21 & 6,36 & 4,29 & 4,38 \\
\hline
\end{tabular}

Tabel 4. Uji Stabilitas F7 metode Freeze-Thaw

\begin{tabular}{ccccccc}
\hline Hari Ke- & Konsistensi & $\begin{array}{c}\text { Organoleptis } \\
\text { Warna }\end{array}$ & Bau & Homogenitas & pH & $\begin{array}{c}\text { Pemisahan } \\
\text { Fase }\end{array}$ \\
\hline 0 & Semipadat & Putih gading & Khas vanilin & Homogen & 4,45 & Tidak Ada \\
4 & Semipadat & Putih gading & Khas vanilin & Homogen & 4,30 & Tidak Ada \\
8 & Semipadat & Putih gading & Khas vanilin & Homogen & 4,22 & Tidak Ada \\
12 & Semipadat & Putih gading & Khas vanilin & Homogen & 4,12 & Tidak Ada \\
16 & Semipadat & Putih gading & Khas vanilin & Homogen & 4,19 & Tidak Ada \\
\hline
\end{tabular}


Tabel 5. Uji Stabilitas F7 pada penyimpanan suhu ruang $\left(25^{\circ} \mathrm{C}\right)$

\begin{tabular}{ccccccc}
\hline \multirow{2}{*}{ Hari Ke- } & Konsistensi & $\begin{array}{c}\text { Organoleptis } \\
\text { Warna }\end{array}$ & Bau & Homogenitas & pH & $\begin{array}{c}\text { Pemisahan } \\
\text { Fase }\end{array}$ \\
\hline 0 & Semipadat & Putih gading & Khas vanilin & Homogen & 4,45 & Tidak Ada \\
4 & Semipadat & Putih gading & Khas vanilin & Homogen & 4,36 & Tidak Ada \\
8 & Semipadat & Putih gading & Khas vanilin & Homogen & 4,34 & Tidak Ada \\
12 & Semipadat & Putih gading & Khas vanilin & Homogen & 4,50 & Tidak Ada \\
16 & Semipadat & Putih gading & Khas vanilin & Homogen & 4,07 & Tidak Ada \\
\hline
\end{tabular}

\section{KESIMPULAN}

Berdasarkan hasil optimasi basis diperoleh F7 (kombinasi carnauba wax dan microcrystaline wax dengan perbandingan $6 \%: 9 \%$ ) sebagai formula optimal basis lip cream dengan karakteristik organoleptis berwarna putih gading, berbau khas vanilin, berbentuk semipadat, dan homogen serta karaketristik fisika dan kimia memiliki daya sebar $6,1 \mathrm{~cm}$, daya lekat lebih dari 60 detik, memiliki nilai viskositas 18.000 cPs dan nilai $\mathrm{pH} 4,38$ serta stabil terhadap pengaruh perubahan suhu selama 16 hari.

\section{DAFTAR PUSTAKA}

[1] Ditjen POM. 1985. Formularium Kosmetika Indonesia. Departemen Kesehatan RI: Jakarta. Hal. 83-86, 195-197.

[2] Adliani, Nur., et al, 2012. Formulasi Lipstik Menggunakan Zat Warna Dari Ekstrak Bunga Kecombrang (Etlingera elatior (Jack) R.M.Sm.), Journal of Pharmaceutics and Pharmacology, 1 (2), 87-94.

[3] Butler, Hilda et al, 2000. Poucher's Perfumes, Cosmetics and Soaps $10^{\text {th }}$ Edition. Kluwer Academic Publishers : London.

[4] Tranggono, R. I. S., Latifah, F, 2007. Buku Pegangan Ilmu Pengetahuan Kosmetik. PT Gramedia Pustaka Utama: Jakarta.

[5] Jellineck, J. S, 1976. Formulation and Function of Cosmetics. Wiley Interscience: New York.
[6] Farima, Dev, 2009. Karakteristik Ekstraksi Simplisia Tumbuhan Bunga Mawar (Rosa hybrida) serta Formulasinya danlam Sediaan Bibir. Skripsi. Universitas Sumatera Utara: Medan.

[7] Departemen Kesehatan Republik Indonesia. 1979. Farmakope Indonesia Edisi Ketiga. Ditjen POM: Jakarta.

[8] Robert, V., Mcdermott P, 2007. Liquid Lip Gloss Compositions with Enhanced Shine.

[9] Aini, Sofia N. 2013. Mutu Fisik dan Volunter Formulasi Sediaan Lipstick dengan Pewarna Alami dari Ekstrak Antosianin Bunga Pukul Empat (Mirabilisjalapa L.). Karya Tulis Ilmiah. Akademi Farmasi Putra Indonesia: Malang.

[10] Vishwakarma, B., Dwivedi S., Dubey K., Joshi H, 2011. Formulation and Evaluation of Herbal Lipstick, International Journal of Drug Discovery \& Herbal Research, 1(1), 18-19.

[11]Priani, Sani Ega et al, 2013. Formulasi Sediaan Emulgel Untuk Penghantaran Transdermal Ketoprofen, Acta Pharmaceutica Indonesia, 38 (1).

[12] Asyifaa, Dinar Assy., et al, 2017. Formulasi Lip cream dengan Pewarna Alami dari Bunga Rosella (Hibiscus sabdariffa L.) serta Uji Stabilitasnya, SPeSIA (Seminar Penelitian Sivitas Akademika Unisba),3 (2). 